\title{
Participação e Comportamento Político no Estado de São Paulo, 1990*
}

\author{
Marcelo Costa Ferreira \\ Doutorando em Ciência Política - IUPERJ
}

\begin{abstract}
Resumo
O objetivo deste trabalho é analisar a associação entre participação política e comportamento eleitoral. As evidências empíricas são originadas a partir da análise de uma pesquisa de opinião realizada no estado de São Paulo em 1990 pelo IBOPE. A partir da análise dos gráficos de correspondência, conclui-se que o voto e as tendências ideológicas de esquerda estão associadas entre si, mas essa evidência não exclui uma associação entre voto na direita e associativismo. Em resumo, poucas modalidades de participação política estão associadas com o comportamento eleitoral, e apatia política parece estar relacionada com a parca credibilidade da atuação na política enquanto mecanismo de representação de interesses e negociação de conflitos.
\end{abstract}

Palavras-chave: Eleições, Associativismo, Participação Política, Participação Eleitoral, Política Brasileira.

\begin{abstract}
The purpose of this article is to analyze the relationship between political participation and electoral behavior. Empirical evidence comes from a survey conducted in São Paulo by the IBOPE in 1990. The main finding suggests that voting and left-wing trends are correlated. However, this finding does not exclude an association between rightist voting and political participation. In short, few modalities of participation are related to electoral behavior, and political apathy should be correlated with few credibility in politics as mechanism of representation and conflict management.
\end{abstract}

Key words: Political participation, Electoral participation, Associativity, Brazilian politics.

- Este estudo teve apoio financeiro do Conselho Nacional de Desenvolvimento Científico e Tecnológico, CNPq. Gostaria de agradecer a enorme generosidade e paciência de Wanderley Guilherme dos Santos, Rachel Meneguello e Vitor Luiz Cooke Vieira, além do apoio de Maria das Graças Plá Sanchez e Paula Cencig. Sem o desprendimento deles, este trabalho não teria sido possível. Destaco também que a qualidade deste estudo foi incrementada de forma significativa através dos comentários e sugestões do referee anônimo, além da leitura atenta de Paulo Leal e das conversas que tive sobre o tema deste artigo com Mônica Mata Machado de Castro, que foram fonte de inspiração para redigir este texto. Sou grato a todos, mas sou o único responsável pelas limitações e eventuais falhas que este estudo possa apresentar.

Este estudo analisa uma pesquisa pertencente ao acervo do CESOP/UNICAMP, tendo sido originalmente idealizada e executada pelo IBOPE. A análise dos dados desenvolvida neste artigo é de minha completa autoria, não constituindo um parecer oficial das instituições mencionadas. 


\section{Introdução}

As eleições de 1989 foram um marco na política brasileira. A ocorrência de forte polarização entre as candidaturas de esquerda (Lula) e direita (Collor), bem como, em seguida, o surgimento de diversas forças políticas muito influentes durante a década de 1990 nos âmbitos políticos regional e nacional, representaram a afirmação de uma nova geração de políticos profissionais nos cenários legislativos e executivos.

Apesar das transformações socioeconômicas observadas a partir de 1960, e as transformações específicas do cenário político a partir de 1989, as taxas de participação política entre o final da década de 1980 e meados de 1996 mostram-se muito baixas, conforme revela Ferreira (1999a), ao analisar dados sobre a participação em 1998 e 1996 nas regiões metropolitanas de São Paulo, Porto Alegre, Salvador, Rio de Janeiro e Fortaleza. As razões para esse fato não parecem se relacionar a condicionantes socioeconômicos, (Ferreira, 1999b). Então, surge uma questão: o quê explicaria a apatia associativa do brasileiro?

O objetivo deste artigo consiste em discutir esta questão, propondo como uma possível estratégia de análise a relação entre a participação, o comportamento e a opinião eleitoral. As citadas associações serão examinadas a partir da interpretação dos dados de uma pesquisa de opinião aplicada em 1990 no Estado de São Paulo pelo Instituto Brasileiro de Opinião Pública e Estatística, Ibope. Seu desenho amostral consiste numa seleção por quotas, incluindo 800 eleitores.

Este texto está dividido em mais duas partes: na seção subseqüente, apresento uma revisão bibliográfica concisa sobre a conexão entre participação e comportamento eleitoral, para, em seguida, explorar a análise da relação entre ambas no estado de São Paulo, em 1990, a partir dos gráficos de análise múltipla de correspondência. $\mathrm{Na}$ conclusão, estão resumidos os principais pontos deste artigo.

\section{Participação e Comportamento Político}

A participação política tem sido considerada um fenômeno multidimensional e não restrito apenas a um modalidade exclusiva de atuação eleitoral, como destacam Sabucedo e Arce (1991) por exemplo, no que tange à participação eleitoral. Esse fenômeno pode assumir diversas facetas: desde o engajamento mais ou menos atuante no processo eleitoral até a inserção em associações de moradores e de cunho religioso. Coerente com este argumento Conge (1988) defende a necessidade de entender o fenômeno da participação de forma abrangente, criticando a adoção de definições muito restritas. 
A bibliografia normalmente tem acentuado a existência de grupos, aglomerados ou conjuntos de distintas modalidades de participação política, sejam eles identificados pela análise fatorial, multidimensional ou de conglomerados (Verba \& Nie, 1972 p.384386). No caso dessas análises, destaco duas características: a primeira seria que a participação não eleitoral provocaria nas pessoas um aumento do seu respectivo interesse em outras modalidades de atuação na política; a segunda seria inversa à primeira, ou seja, não haveria relação entre a participação eleitoral e participação numa associação de bairro ou em sindicatos.

Um exemplo do primeiro desses aspectos é o estudo de Erickson e Nosanchuk (1990), segundo o qual a teoria sobre participação política (Almond \& Verba, 1963) aponta a relação entre associativismo e diversas outras modalidades de participação. Pertencer ou atuar numa associação fomenta características como o debate político, a organização coletiva e a conscientização política. Também compartilham esse argumento as pesquisas de Baumgartner e Walker (1987), Leighley (1996) e Huckfeldt (1979) ${ }^{1}$. A pesquisa de Erickson e Nosanchuk (1979) testa essa hipótese em um estudo de caso de um agrupamento apolítico, uma associação de jogadores de bridge, e seus resultados corroboram parcialmente a teoria, qual seja, apenas os que conversam sobre política na associação participam de outras modalidades.

O segundo aspecto consiste na não associação entre a participação eleitoral e as suas diversas facetas, como votar, colar panfletos, convencer outras pessoas a votar em um dado candidato, entre outras, com modalidades de participação política conhecidas como associativismo ou a filiação a sindicatos. Esse aspecto apresenta alguma semelhança com o estudo de Polock (1982). Segundo este autor, a correlação entre todas as modalidades de participação política entre si não é automática, ou seja, determinados tipos de participação política tendem a formar conglomerados de modalidades de atuação política.

No Brasil, o trabalho de Castro (1985) analisa essa questão, comparando duas pesquisas por amostragem realizadas em 1976 em Juiz de Fora e Presidente Prudente. Essa autora estava interessada em analisar a relação entre o voto na Arena ou MDB e a filiação dos eleitores a uma determinada associação profissional ou sindical, com a hipótese de que o voto oposicionista estaria associado à participação política. A tese de Lipset (1963) é de que a participação política nos setores populares fomenta o voto de oposição. Porém, segundo a análise de dados elaborada pela autora, a participação política está associada ao conservadorismo na cidade de Presidente Prudente, enquanto o inverso ocorre em Juiz de Fora.

\footnotetext{
${ }^{1}$ Gilles e Dantico, 1982) concordam com o respectivo ponto, mas afirmam que este tipo de associação é fraca quando se considera o status social dos indivíduos em associações de bairro.
} 
Em suma, a bibliografia aponta que a relação entre participação e comportamento eleitoral não é estável. Ou seja, a participação política pode influenciar a inserção em outras modalidades de atuação, mas a tendência é a organização de conglomerados de formas de participação política. Pode também haver ou não uma relação entre o pertencimento a associações e o voto conservador. No próximo tópico, analiso esta questão para o Estado de São Paulo em 1990.

\section{Participação e Comportamento Político no Estado de São Paulo, 1990}

São Paulo é o maior estado brasileiro em termos populacionais e econômicos, concentrando grandes indústrias, o setor financeiro e diversas atividades de serviços - a participação percentual de São Paulo no PIB nacional foi em torno de $35 \%$ entre os anos de 1990 e 1994 (SEADE, 2000). O peso eleitoral de São Paulo é considerável, e o seu eleitorado apresenta uma papel muito significativo em qualquer eleição presidencial - em 1990, por exemplo, os eleitores paulistas eram $22,3 \%$ do eleitorado brasileiro ${ }^{2}$. Contudo, o eleitorado paulista apresenta, em termos gerais, taxas de participação política muito reduzidas, não correspondentes à relevância política e econômica desse estado. É o que apresenta a Tabela I.

Os dados da pesquisa de 1990 mostram, entretanto, a existência de interesse em política, embora não traduzido em participação. Assim, 79\% dos entrevistados assistiram à propaganda política na televisão, enquanto $68,3 \%$ conversaram sobre política com a família. Destacam-se como atuantes os que participam em clubes recreativos, $30,8 \%$; e os que são ou já foram sindicalizados, $28,4 \%$. Além disso, aproximadamente $85 \%$ dos que pertencem a sindicatos não votam e não comparecem em suas respectivas assembléias. Observa-se que os resultados condensados na Tabela I são coerentes com diversos estudos sobre participação já realizados no Brasil, ver Castro (idem) e Ferreira (1999a).

\footnotetext{
${ }^{2}$ Percentual calculado a partir das informações disponíveis em Leex (2000).
} 
TABELA I

Participação Política no Estado de São Paulo - 1990 (\%)

\begin{tabular}{|c|c|c|}
\hline \multirow[t]{2}{*}{ Modalidade de Participação } & \multicolumn{2}{|c|}{ Pertencimento ou Atuação Política } \\
\hline & Sim & Não \\
\hline \multicolumn{3}{|l|}{ Participação Política } \\
\hline Clube Recreativo & 30,8 & 69,3 \\
\hline Associação Profissional & 7 & 93 \\
\hline Associação Beneficiente & 14,1 & 85,9 \\
\hline Grupo de Defesa dos Direitos da Mulher & 1,4 & 98,6 \\
\hline Grupo de Defesa dos Direitos Raciais & 2,4 & 97,6 \\
\hline Associações de Bairro ou de Moradores & 8,3 & 91,8 \\
\hline Comunidades Eclesiais de Base & 7,3 & 92,8 \\
\hline $\begin{array}{l}\text { É ou já foi filiado ao Sindicato de sua categoria } \\
\text { ? }\end{array}$ & 28,4 & 71,6 \\
\hline Partidos Político & 6,1 & 93,9 \\
\hline Greve & 17,5 & 82,5 \\
\hline \multicolumn{3}{|l|}{ Participação Eleitoral } \\
\hline Boca de Urna & 6,5 & 93,5 \\
\hline Deu dinheiro para campanha de candidato & 2,9 & 97,1 \\
\hline Trabalhou como fiscal de partido & 2,3 & 97,8 \\
\hline Recolheu dinheiro para campanha & 2 & 98 \\
\hline Fez Propaganda de Candidatos & 36,5 & 63,5 \\
\hline Distribuiu material de Propaganda Política & 13 & 87 \\
\hline Usou camiseta, button, adesivo & 19 & 81 \\
\hline Comícios, passeatas, carreatas, e etc. & 27,6 & 72,4 \\
\hline Persuadiu voto alheio & 39,5 & 60,5 \\
\hline $\mathrm{N}$ & 800 & \\
\hline
\end{tabular}

Pesquisa de Opinião Pública. IBOPE - 19 a 28 de Fevereiro de 1990

Tabulação realizada pelo Autor.

Contudo, a participação eleitoral, excluindo o exercício do voto, não está relacionada à atuação política não eleitoral, conforme revela o Gráfico $\mathrm{I}^{3}$. A participação do tipo eleitoral não está associada à dimensão associativa da atuação na política, e entre esses dois grupos, percebe-se o conjunto da nãoparticipação. Apenas a participação em carreatas, o uso de camiseta e bonés e a realização de propaganda para candidatos apresentam alguma relação com o associativismo. Tendo em vista esse fato, apenas a participação em carreatas foi mantida nas análises multivariadas subseqüentes. O mesmo não ocorre com a dimensão do exercício do voto, a opinião eleitoral e a participação.

\footnotetext{
${ }^{3}$ O Gráfico I consiste num diagrama de análise de correspondência, ver Hair (1995). São duas as finalidades desta técnica estatística. A primeira busca representar as associações entre as categorias de um conjunto de variáveis. Quanto maior a associação, mais próximos no gráfico estarão os atributos, e o mesmo ocorre com a fraca (ou inexistência de) associação. Por exemplo, no Gráfico I, a participação em grupos de defesa da mulher está associada à filiação a entidades de defesa dos direitos raciais. Porém, não existe associação entre o uso de bonés numa eleição e o pertencimento a grupos de defesa feminista. A principal diferença é que, no primeiro caso, as duas categorias estão próximas no gráfico, o que não ocorre no segundo exemplo. A segunda finalidade é a identificação de grupos de categorias associadas entre si. No caso do gráfico I, existe um aglomerado composto pela associação entre a prática da boca de urna e a filiação a associações beneficientes, profissionais e de bairro; enquanto um outro grupo consiste na associação entre pertencimento a grupos de defesa da mulher ou a entidades de defesa de direitos raciais
} 
GRÁFICO I

Grupos de Associação entre as Diversas Modalidades de Participação Política no Estado de São Paulo, 1990 Análise Múltipla de Correspondência ${ }^{4}$

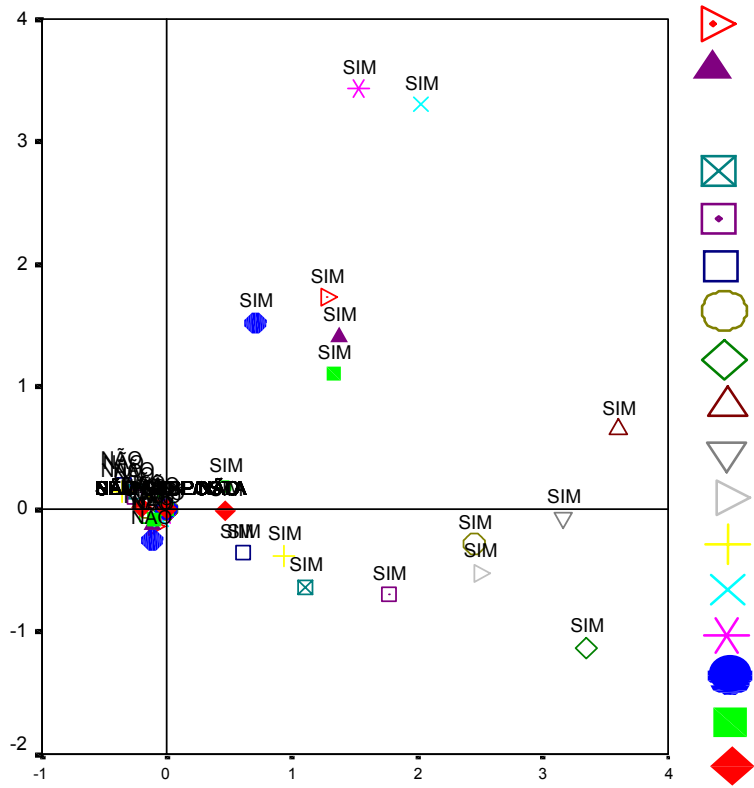

CEB

Associação de Bairro

Convenceu Out s/Candidato

$\bigotimes$ Usou Camiseta, Boné,

- Distribuiu Material de Propaganda

Fez Propaganda de Candidato

Partido Político

Recebeu Dinheiro Campanha

Fiscal Partido em Eleições

Deu Dinheiro Campanha

Boca de Urna

Comício, Passeata,

Grupo Defesa Direitos Raciais

Grupo Defesa Direitos da Mulher

Associcação Beneficiente

Associação Profissional

Clube Recreativo

Em 1990, o eleitorado do estado de São Paulo pode ser considerado conservador: $33 \%$ dos entrevistados se identificaram como de direita, $23,6 \%$ não assumiram postura ideológica (seja afirmando que é neutro politicamente, ou que não sabe ou não respondeu à questão formulada). O voto preferido para Presidente da República no primeiro turno em 1989 foi em Collor, 31,4\%, (no segundo turno, 56,9\%) o apoiaram, seguido de Lula, 21,5\%; Covas, 16,3 e Maluf, $14,1 \%$, que também foi apontado como o candidato preferido para governar o estado (com a preferência de $31,5 \%$ dos entrevistados) ${ }^{5}$. O Gráfico II descreve a relação entre essas variáveis.

Quatro grupos são identificados no Gráfico II: a esquerda, a direita de cunho eleitoral, a direita de cunho associativo e os apáticos. O primeiro agrupamento consiste na associação entre a identificação partidária pelo PSDB, $P T, P C B$ e PC do B com o voto no primeiro e no segundo turnos em Lula. $O$ segundo conglomerado reside nos partidos de tendência ideológica direitista com parca expressão eleitoral, ou seja: o PDS e o PTB. O terceiro grupo é a direita eleitoral: o voto em Collor no primeiro e no segundo turno está associado ao voto

\footnotetext{
${ }^{4} \mathrm{O}$ programa estatístico utilizado para gerar os gráficos da análise de correspondência foi o SPSS.

${ }^{5} \mathrm{O}$ leitor interessado na análise entre identificação partidária e comportamento eleitoral encontrará uma análise mais detalhada sobre este tema no trabalho de (Singer, 2000).
} 
em Guilherme Afif e Maluf apenas no primeiro turno, além da identificação partidária com o PFL e o PRN. Já os apáticos constituem um grupo bem heterogêneo, que inclui os que não têm opinião e os eleitoralmente alienados (que votaram em branco ou nulo). Além disso, o voto em Covas ou Ulisses é uma característica deste grupo. Um outro ponto de destaque consiste na participação em greves, sindicatos e clubes recreativos e comícios/passeatas e carreatas, e que apresenta um associação com o voto presidencial em Lula.

\section{GRÁFICO II}

Participação Política, Voto Presidencial e Identidade Partidária

no Estado de São Paulo, 1990

Análise Múltipla de Correspondência

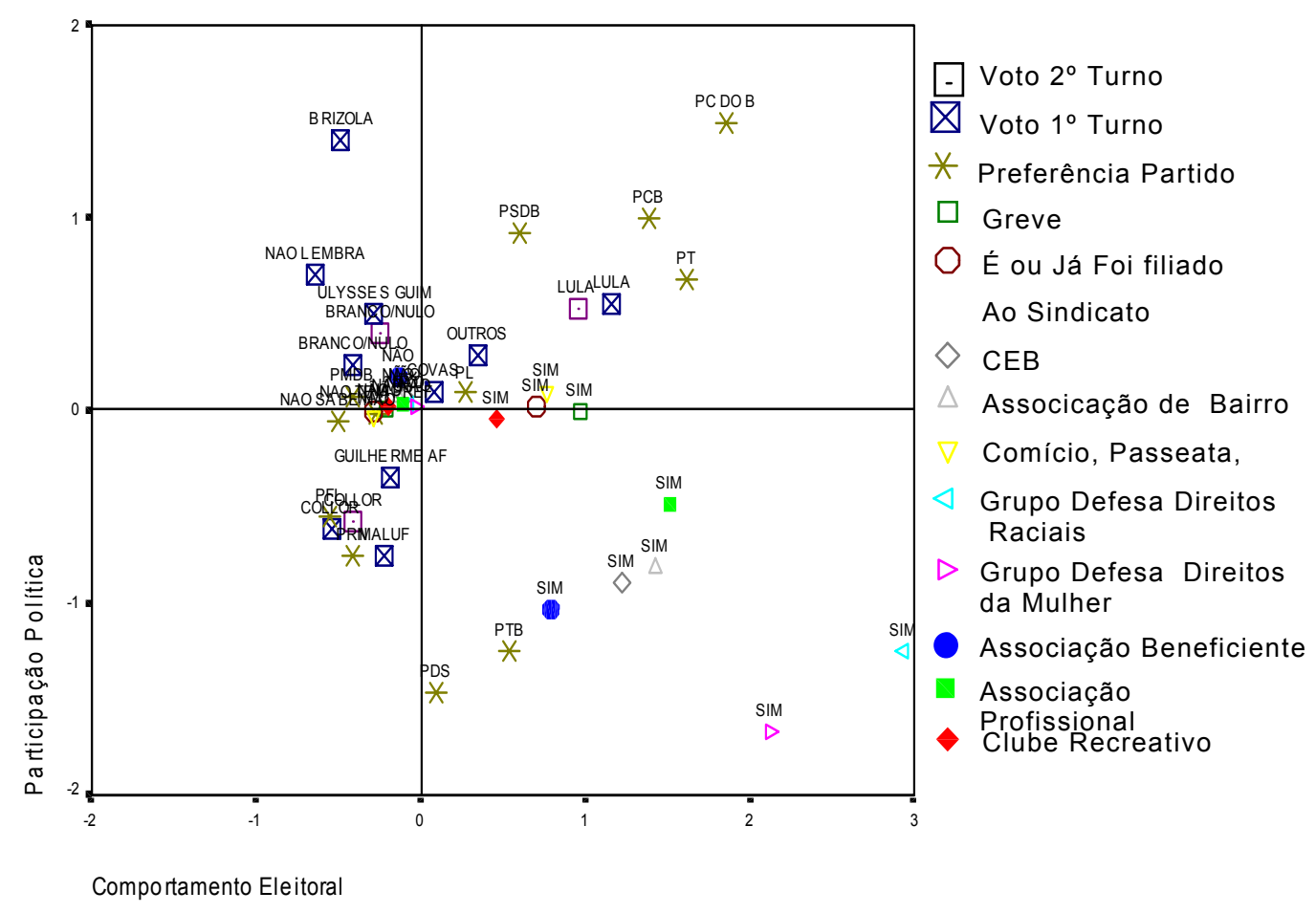


A análise do Gráfico II apresenta as dificuldades de legitimação eleitoral da esquerda. $\mathrm{O}$ apoio a Lula é baseado em movimentos sociais organizados, enquanto a direita, no segundo turno, une-se para alcançar a hegemonia eleitoral. O principal problema da candidatura Lula, sugerido pela interpretação dos dados é conseguir no segundo turno, o voto que não foi para uma candidatura de esquerda no primeiro turno para o segundo. Contudo, como a participação política organizada é baixa, o principal trunfo de Lula aparece minimizado, uma vez que a maioria do eleitorado de direita não participa de forma organizada.

Um outro ponto é a relação entre participação política e a identificação partidária. Algumas modalidades de participação estão associadas à identificação partidária com siglas de direita, enquanto outras estão relacionadas a partidos de esquerda. Por exemplo: a identificação com o PDS e o PTB apresenta relação com a participação em associações beneficientes ou profissionais e de bairros. Por outro lado, existe associação entre variáveis de participação política (ou seja: fizeram greve, são filiados a sindicatos ou clubes recreativos) e o voto no primeiro e no segundo turnos na eleição presidencial de 1989 em Lula. A participação política em movimentos organizados pode estar associada a posições de direita e de esquerda. Em outras palavras: algumas modalidades de atuação na política tendem a estar associadas com comportamento político mais próximo ao da direita, enquanto outros estão relacionadas a posturas eleitorais de esquerda.

A associação entre participação política e voto direitista é bastante complexa. Os candidatos com maior expressão eleitoral nas eleições presidenciais de 1989 e para governador em 1990 - no último caso, no momento da aplicação da pesquisa de opinião revela que os candidatos com maior performance eleitoral não apresentam expressiva associação com as variáveis de pertencimento a entidades associativas. Assim, as categorias que representam o voto em Collor ou Maluf estão distantes no Gráfico II em relação aos atributos que indicam filiação a algum movimento organizado. Este panorama, contudo, não ocorre com os partidos de esquerda - como o PSDB, PT entre outros . Os partidos de direita, como o PTB e o PDS apresentam um situação ambígua. Neste último caso, a posição desses dois últimos partidos é eqüidistante em relação à participação política , por exemplo, entre entidades beneficientes e o voto nos grandes candidatos da direita nas eleições para os executivos nacional e estadual.

Existe também um conjunto de modalidades de participação que está no "centro" dos quatro aglomerados de representação da associação entre participação, voto e identidade partidária: a filiação, presente ou passada, a sindicatos e a participação em greves. Estas duas formas de atuação na política são as únicas no Gráfico II que podem apresentar alguma associação com o voto nos candidatos da direita ou de tipo em branco ou nulo. Ao contrário da proposição do senso comum, a associação entre identificação com partidos de esquerda e atuação sindical não é tão expressiva. Por outro lado, a participação sindical apresenta uma relação expressiva com o voto em Lula - principal candidato do maior partido de esquerda no Brasil, o PT. 
A análise da associação entre participação política, o voto para senador e para governador nas eleições de 1990 no estado de São Paulo é apresentada no Gráfico III. Naquele ano, os entrevistados pelo IBOPE declararam que, se a eleição fosse realizada naquele momento, Maluf teria $31,5 \%$ dos votos para o executivo estadual, seguido de Sílvio Santos com 19,1\%. A pesquisa constatou também que $18,9 \%$ declararam que não votariam, ou ainda, não sabiam ou não quiseram opinar.

Para a eleição no Senado, no mesmo ano, Eduardo Suplicy, candidato do PT, e Franco Montoro, do PSDB, ficariam tecnicamente empatados, com 20,4\% e 22,8\%, respectivamente. Uma outra votação expressiva foi dada ao não-voto e a omissão de opinião eleitoral, traduzida por $29,5 \%$. A expressiva intenção de voto em Suplicy talvez possa ser um reflexo do voto dado a uma personalidade importante na história da consolidação do PT no estado, ou de uma modalidade de voto de protesto, da mesma forma que ocorreu com o voto dado em 1986 a Luiza Erundina, prefeita da capital paulista entre 1988 e 1992. O eleitorado do Estado de São Paulo em 1990 - segundo as evidências analisadas neste artigo - não poderia ser considerado progressista, mas consiste num fato indiscutível que uma parcela expressiva manifesta uma significativa insatisfação com os candidatos às eleições.

O Gráfico III apresenta duas grandes aglomerações. A primeira é composta pela associação entre o voto em Suplicy e Papa JR para o Senado; Montoro para o governo e a participação em CEBs, associações de bairro, greve, sindicatos e clubes recreativos. A outra dimensão é a não-participação, a não-manifestação de preferência eleitoral e o voto em todos os outros candidatos para o governo e para o Senado. Esta configuração demonstra interessantes evidências da articulação das candidaturas no primeiro segmento com setores organizados da sociedade. Mesmo assim, a associação entre as categorias de filiação a grupos associativos e o voto não são inexistentes, mas são bem fracas.

A relação entre preferência partidária, posição política (direita, esquerda ou centro) e o voto num candidato do PT ao governo do estado com as modalidades de participação política são apresentadas no Gráfico IV. O partido com maior percentual de identificação é o $\mathrm{PT}$, com $13,1 \%$, seguido pelo PMDB, com $4,2 \%$, PDS, com $3,8 \%$ e o PSDB, com $2,4 \%$. Já os partidos de direita apresentam as menores taxas de identificação partidária, mas o mesmo não ocorre na auto-identificação ideológica: $33, \%$ do eleitorado do estado se classificaram como de direita, enquanto $15 \%$ de esquerda, $17,5 \%$ de centro e $33,1 \%$ não sabem, não responderam ou não se auto-classificaram ideologicamente. Além disso, ao serem inquiridos sobre a possibilidade de votar num candidato do PT ao governo, $46 \%$ dos entrevistados declararam que não votariam nesta opção. A análise destes percentuais sugere a existência de quatro vetores ideológicos no eleitorado paulista: a esquerda, representada pelo 
PT; a direita; categorias intermediárias de opção de centro e os alienados em relação à política.

GRÁFICO III

Participação Política, Voto no Senador e Governador

no Estado de São Paulo, 1990

Análise Múltipla de Correspondência

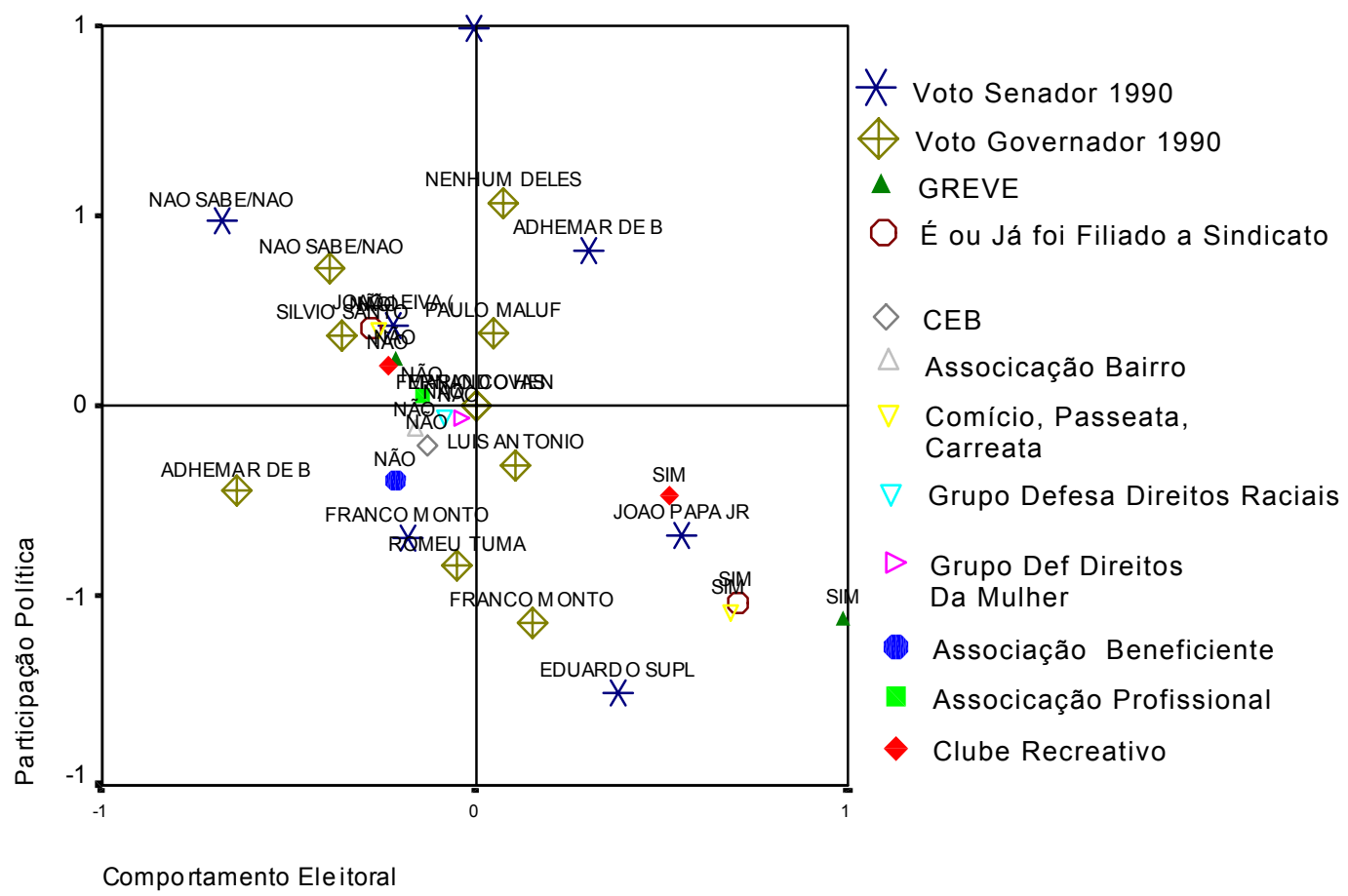

A análise de correspondência efetuada no Gráfico IV praticamente replica a interpretação dos percentuais das citadas variáveis. A posição ideológica de esquerda, a identificação com o PT, o voto em Lula no segundo turno nas eleições presidenciais de 1989 e a opção pelo candidato do PT para o governo do estado compõem uma das configurações no mencionado Gráfico IV. Um segundo aglomerado pode ser considerado como de direita, que reside na identificação partidária com o PRN, PMDB, o voto em Collor no segundo turno nas eleições presidenciais de 1989. Um conjunto de categorias intermediárias consiste na opção ideológica pelo centro - que confirma o tradicional clichê sobre a política brasileira. A citada categoria está muito mais próxima da direita do que um ponto eqüidistante entre a esquerda e a direita, apesar da forte associação deste segmento com a participação em CEBs, greves ou sindicatos - 
o que constitui um aparente paradoxo. Curioso é que, à época, a identificação partidária com o PSDB assumia uma identificação muito maior com a esquerda do que com posições políticas de centro ou de esquerda. Enfim, uma outra configuração seria expressa pela posição de alienação política. Ela seria manifestada pela não participação, não emissão de opinião ou preferência eleitoral, voto em branco, posição neutra em relação à possibilidade contrafactual do estado ser governado pelo PT.

\section{GRÁFICO IV}

Participação Política, Identidade Partidária, Voto no $2^{\circ}$ turno Presidencial e Rejeição ou Aceitação do PT no Estado de São Paulo, 1990 Análise Múltipla de Correspondência

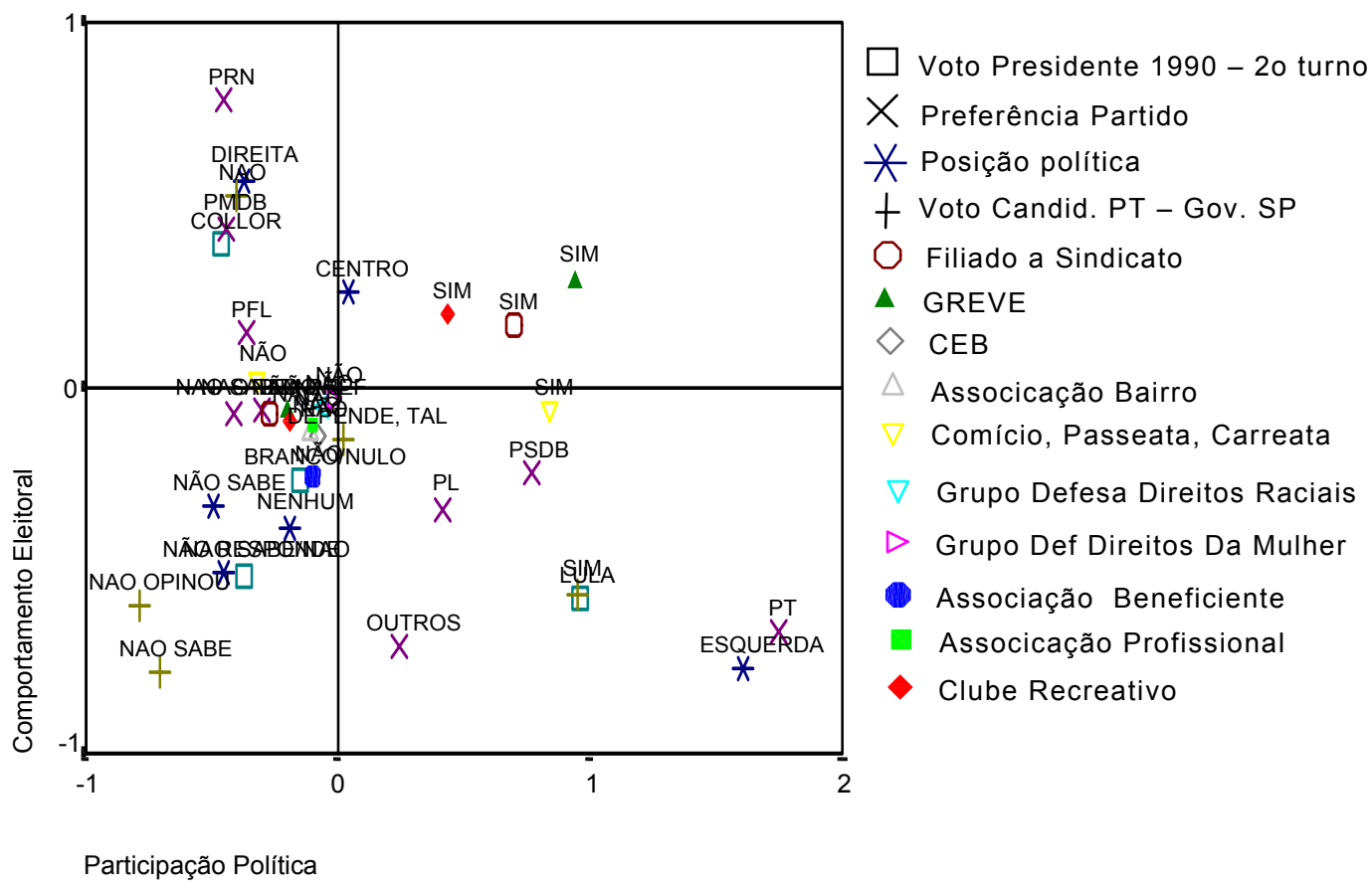

Em resumo, tendo em vista a questão proposta inicialmente neste artigo, cujo objetivo era relacionar comportamento eleitoral e participação política, quais seriam as relações entre as múltiplas dimensões desses dois componentes do comportamento político? Nos três gráficos de análise múltipla de correspondência analisados, as dez categorias de atuação na política (ou seja, a participação não eleitoral) só apresentam alguma associação com o comportamento eleitoral no Gráfico II (relação entre participação política, voto presidencial e identidade partidária). Das dez categorias de participação não eleitoral, nove aparecem no Gráfico II, sendo que apenas a participação 
em grupos de defesa dos direitos da mulher ou de direitos raciais não apresenta associação com as categorias das outras variáveis presentes na análise. Contudo, o mesmo não ocorre nos Gráficos III (participação política, voto no Senado e no governo do Estado) e IV (participação política, identidade partidária, voto no $2^{\circ}$ turno presidencial e rejeição ou aceitação do PT).

As categorias referentes à participação em greves, clube recreativo e pertencimento presente e passado a sindicatos apresentam alguma influência no Gráfico III e IV. As outras categorias de atuação na política presentes nas outras variáveis de participação sequer aparecem nestes dois últimos gráficos. As três respectivas modalidades de participação apresentam, nos Gráficos II e IV, associação com o comportamento eleitoral, tanto de esquerda quanto de direita, enquanto a identificação partidária apresenta expressiva associação com o voto de direita e de esquerda no Gráfico IV.

A relação entre participação política e comportamento eleitoral parece ser bem expressiva num contexto de eleições presidenciais. Porém, um pequeno número de modalidades de participação política parece ter alguma relação com a dimensão eleitoral. Por outro lado, a não participação eleitoral está presente em todos os gráficos, e costuma estar associada ora à não emissão de opinião política e a alienação eleitoral (voto em branco, nulo, por exemplo), ora ao voto em candidatos de direita.

Logo, a corrente que prescreve que os valores de desvalorização da política, entendida como arena de representação de interesses e de negociação de conflitos, resultam em apatia associativa, parece estar sendo corroborada pela análise dos gráficos de correspondência. No que respeita à participação eleitoral, o eleitor apático tanto vota na direita, quanto se exclui do processo eleitoral. Contudo, quando o eleitor participa - ou participou - em sindicatos, ou é filiado a entidade recreativa, ou já fez greves, este tipo de participação política pode tanto estar associada ao comportamento político de esquerda quanto ao de direita. Esse aspecto é coerente com o estudo de Castro (1985), e será discutido em maiores detalhes no próximo tópico, onde estão resumidos os principais pontos deste estudo. 


\section{Conclusões}

Este artigo investigou a relação entre a participação política e os fatores exclusivamente políticos, enfocando a relação entre as modalidades de participação política entre si, além de investigar a associação delas com o comportamento político do eleitorado do estado de São Paulo em 1990.

A análise dos dados apontou evidências empíricas da parca associação entre participação política e comportamento eleitoral, ou seja: a atuação política de cunho não eleitoral apresenta relação fraca com o voto, a identidade partidária e aceitação ou não da possibilidade contrafactual do estado ser governado pelo PT. A maior parte das formas de atuação política sequer apareceu nos gráficos de análise de correspondência. Contudo, quando alguma associação ocorre entre a dimensão participativa e a eleitoral, percebe-se que algumas modalidades de participação podem estar associadas tanto ao voto de direita quanto de esquerda.

O eleitorado paulista apresenta uma fraca inserção nas modalidades de participação política analisadas neste estudo - com exceção da filiação a clubes recreativos, é o pertencimento a sindicato de sua categoria, greve. No que tange à participação eleitoral, também são expressivos os percentuais de eleitores que já persuadiram o voto alheio, fizeram propaganda de candidatos ou participaram de comícios, passeatas ou carreatas. Os paulistas não são tão apáticos em comparação com os resultados de outros estudos realizados sobre participação política. (Ferreira, 1999a ; Castro, 1985). Entretanto, também estão muito distantes do ideal do cidadão cívico - que é caracterizado por um significativo envolvimento na política.

A análise das associações entre as diversas modalidades de participação política entre si é coerente com outros estudos já realizados na literatura (Verba \& Nie, 1972), ou seja, existem grupos de modalidades de participação que formam aglomerados entre si. No caso deste estudo observam-se três grupos bem distintos de participação: a participação de cunho associativo, a eleitoral e o pertencimento a grupos de defesa dos direitos da mulher e de grupos raciais.

$\mathrm{Na}$ análise da associação entre participação política, voto presidencial e identidade partidária, um primeiro ponto de destaque é a associação entre a não participação eleitoral e a alienação eleitoral ou o voto na direita. Nas eleições presidenciais de 1989, os votos da direita se unem no segundo turno, o que não ocorre com a candidatura de esquerda. Da mesma forma, existe associação entre a identificação partidária com partidos de direita e associações beneficientes ou de bairro, enquanto o pertencimento a clubes recreativos, sindicatos ou a atuação em greve podem tanto estar associadas a comportamentos políticos de esquerda quanto de direita. De uma forma geral, as modalidades de participação que caracterizam-se pela geração de bens públicos de qualquer natureza tendem a ter uma inserção individual que está associada à identidade com pequenos partidos de direita, como o PDS ou PTB. Já as modalidades de 
atuação política que têm objetivos políticos mais explícitos (greve ou pertencimento a sindicatos) podem tanto estar associadas à identificação ou o voto presidencial em candidatos ou partidos de esquerda.

Um segundo ponto de destaque é a relação entre participação política, voto para o Senado e para governador; ou participação política, identidade partidária, voto no segundo turno presidencial e rejeição ou aceitação de o governo do estado ser exercido pelo PT, onde percebe-se que a maior parte das modalidades de participação política analisadas não estão associadas a outras facetas do comportamento eleitoral. De uma forma geral, apenas o pertencimento a clubes recreativos, sindicatos ou atuação em greves - além da não participação política - estão presentes em todos gráficos analisados.

Contudo, a identidade partidária parece apresentar um associação com o comportamento eleitoral muito mais robusta do que a participação política. Coerente com o estudo de Singer (2000), o eleitorado paulista apresenta segmentos claramente identificados com a esquerda, direita, centro e apáticos em termos políticos. Em uma eleição presidencial, os votos nas candidaturas de direita se unem no segundo turno, e os alienados podem tanto apoiar a direita quanto se manterem à margem do processo eleitoral.

Em resumo, como poucas modalidades de participação política interferem neste processo eleitoral, e quando têm alguma influência, podem tanto estarem associadas com o comportamento político de esquerda ou de direita, e ainda às vezes apenas com a direita, a associação entre participação política e comportamento eleitoral não é inexistente, mas é bem fraca. Além disso, a não participação política está associada com a não opinião, o voto em branco ou nulo no processo eleitoral. Esta evidência sugere que fatores relacionados à pouca credibilidade da participação política entendida como mecanismo de representação de interesses e de negociação de conflitos, podem estar relacionados à apatia associativa.

\section{BIBLIOGRAFIA}

ALMOND, Gabriel e VERBA, Sidney. (1965), The Civic Culture: Political Attitudes and Democracy in Five Nations. Boston, The Little Brown and Company.

BAUMGARTNER, Frank e WALKER, Jack L. (1987), "Survey Research and Membership in Voluntary Associations". American Journal of Political Science. Vol. 32, $n^{\circ} 4$. Pp908928.

CASTRO, Monica Mata Machado. (1985), "Participação e Comportamento Político". Cadernos DCP. UFMG. N ${ }^{07}$. Setembro. Pp57-83.

CONGE, Patrick J. (1988), "The Concept of Political Participation - Toward a Definition " Comparative Politics, January. 
ERICKSON, Bonnie H. e NOSANCHUK, T.A . (1990), "How an Apolitical association Politicizes". Canadian Review of Sociology and Anthropology. Vol. 27, n² 2. pp206219.

GILLES, Micheal W. e DANTICO, Marilyn. (1982), "Political Participation and Neighborhood Social Context Revisited”. American Journal of Political Science. Vol. 26, n० 1. Pp144-150.

FERREIRA, Marcelo Costa. (1999) "Associativismo e Contato Político nas Regiões Metropolitanas do Brasil: 1988 -1996. Revisitando o Problema da Participação". Revista Brasileira de Ciências Sociais, ANPOCS, № 41, Outubro. Pp90-102.

Socioeconômicos: as Regiões Metropolitanas Brasileiras: 1988-1996". Opinião Pública, CESOP/UNICAMP,Vol. V, junho.pp78-86.

HAIR, Joseph et alli Multivariate Data Analysis with Readings. Nova Jersey, Prentice Hall, 1995. $4^{\circ}$ Ed.

HUCKFELDT, R. Robert. (1979), "Political Participation and The Neighborhood Social Context. American Journal of Political Science. Vol. 23, n 3. pp579-592.

FUNDAÇÃo ESTADUAL DE ANÁlisE DE DADOS DE SÃO PAULO (SEADE), (2000). Participação do PIB do Estado de São Paulo no PIB do Brasil, por Setor de Atividade 1980-1994. http://www.seade.gov.br/cgi-bin/titabpv98/titabp.ksh?sg=IND . 28/06/2000, $16: 42$

LABORATÓRIO DE ESTUDOS EXPERIMENTAIS, (2000). Banco de Dados de Indicadores Políticos, http://www.iuperi.br/Portugues/leex/INDICE.htm. 28/06/2000, $16: 55$.

LEIGHLEY, Jan. (1996), "Group Membership and the Mobilization of Political Participation”. The Journal of Politics. Vol. 58, n² 2. Pp 447-463.

LIPSET, Seymour Martin. (1963). Political Man: The Social Basis of Politics. New York, Anchor Books.

POLLOCK, Philip H. (1982), "Organizations as Agents of Mobilization: How Does Group Activity Affect Political Participation?". American Journal of Political Science. Vol. 26, $\mathrm{n}^{\circ}$ 3. Pp485-503

SABUCEDO, Jose Manuel e ARCE, Constantino. (1991), "Types of Political Participation: A Multidimensional Analysis". European Journal of Political Research. Vol. 20. Pp 93102.

SPSS CORPORATION, SPSS 6.1. (1994), Professional Statistics. Chicago, Marketing Department. SINGER, André. (2000), Esquerda e Direita no Eleitorado Brasileiro. São Paulo, EdUSP.

VERBA, Sidney e NIE, Norman. (1972), Participation in America: Political Democracy and Social Equality. Chicago, The University of Chicago Press. 